\title{
Note on Tongan Orthography and Transcription Conventions
}

The Tongan language has twelve consonants ( $f h k l m n n g p s t v '$ ') and five vowels ( $i$ e $a$ o $u$ ), roughly identical to the sounds of the International Phonetic Alphabet (IPA) that are written with the same symbols, except for $n g$, which is a velar nasal (IPA $\mathrm{n}$ ), and the inverted apostrophe, which represents a glottal stop. Vowels can be phonemically long, in which case the letter is superposed with a macron (e.g., $\bar{a}$ ). This orthography is standardized. Standard reference works on the language continue to be C. Maxwell Churchward's grammar (1953) and bilingual dictionary (1959), although the latter is soon to be superseded by a monolingual dictionary compiled by Melenaite Taumoefolau.

In several chapters, I analyze brief excerpts of talk. The conventions I follow in the transcripts are those established in the sociological tradition of Conversation Analysis, through the work of Gail Jefferson in particular, designed to provide analytic information on the prosodic quality, rhythm, and nonlinguistic vocalizations audible in the recording. While these conventions have been subjected to criticism, they are nevertheless useful because of their readability and the fact that their widespread scholarly usage makes them easily recognizable. Following is a key to relevant transcription conventions.

wordWORD

length of significant pause in seconds, between or within utterances

untimed pauses

(for pauses of less than 0.3 seconds)

abrupt cut-off

forte volume 


\begin{tabular}{|c|c|}
\hline hhhh & $\begin{array}{l}\text { exhalation (number of character indicates } \\
\text { approximate length) }\end{array}$ \\
\hline .hhhh & inhalation \\
\hline wo::rd & nonphonemic segment gemination \\
\hline$?$ & rising pitch (not necessarily in a question) \\
\hline , & slightly rising pitch \\
\hline - & falling pitch (not always at the end of a sentence) \\
\hline ! & animated tempo \\
\hline word $=$ & turn latching (no pause between turns) \\
\hline$=$ word & \\
\hline ((whisper)) & information for which a symbol is not available \\
\hline$(\quad)$ & inaudible material \\
\hline (word) & conjectured material \\
\hline [I985:4:B:360-700] & transcript and page number or recording counter \\
\hline
\end{tabular}

